\title{
The Human/Machine Humanities: A Proposal
}

\author{
Ollivier Dyens \\ Département de langue et littérature françaises, McGill University, 845 Rue Sherbrooke W, Montréal, \\ QC H3A 0G4, Canada; Ollivier.dyens@mcgill.ca
}

Academic Editors: Albrecht Classen and Paul Keen

Received: 29 September 2015; Accepted: 4 February 2016; Published: 1 March 2016

\begin{abstract}
What does it mean to be human in the 21st century? The pull of engineering on every aspect of our lives, the impact of machines on how we represent ourselves, the influence of computers on our understanding of free-will, individuality and species, and the effect of microorganisms on our behaviour are so great that one cannot discourse on humanity and humanities without considering their entanglement with technology and with the multiple new dimensions of reality that it opens up. The future of humanities should take into account AI, bacteria, software, viruses (both organic and inorganic), hardware, machine language, parasites, big data, monitors, pixels, swarms systems and the Internet. One cannot think of humanity and humanities as distinct from technology anymore.
\end{abstract}

Keywords: technology; artificial intelligence; humanity; humanities; big data; parasites; virus; bacteria

\section{Introduction}

"Your trillions of cells-only 10 percent of which, remember, were yours anyway-will become parts of trillions of things. And even the 10 percent wasn't really yours to begin with. You were only borrowed. We've had it backward all along: the body is immortal—it is the soul that dies."

\section{(Jill Sisson Quinn [1])}

We are on the cusp of something very dramatic: our relationship to the world is so distorted by science and technology (genomics, AI, Big Data, etc. ${ }^{1}$ that it now seems difficult to explore humanity and the humanities without probing and questioning their foundations: What does it mean to be human in the 21st century? What does it mean to be human as we draw closer and closer to what Ray Kurzweil calls the Singularity, that moment in time when technological "gravitation" becomes so strong that it pulls the law of physics, the taxonomy of life, the reality of consciousness and the essence of humanity into it?

\section{Rethinking the Foundations}

Evolutionary theory is clear: what we believe to be our primary understanding of what and who we are is not based on cognition and consciousness as we may like to believe, but is embodied in

\footnotetext{
"Most long-range forecasts of what is technically feasible in future time periods dramatically underestimate the power of future developments because they are based on what I call the 'intuitive linear' view of history rather than the 'historical exponential' view. My models show that we are doubling the paradigm-shift rate every decade, as I will discuss in the next chapter. Thus the twentieth century was gradually speeding up to today's rate of progress; its achievements, therefore, were equivalent to about twenty years of progress at the rate in 2000. We'll make another twenty years of progress in just fourteen years (by 2014), and then do the same again in only seven years. To express this another way, we won't experience one hundred years of technological advance in the twenty-first century; we will witness on the order of twenty thousand years of progress (again, when measured by today's rate of progress), or about one thousand times greater than what was achieved in the twentieth century." ([2], p. 11)
} 
our physical body, this strange and awkward device chiselled by and for survival ${ }^{2}$. This material incarnation of male and female, this "thing" that allows us to exist within a limited, chemically defined environment, is probably the angle from which we primarily and even uniquely apprehend the world. Humans, humanity and the humanities, beyond what we may pretend or believe, appear to be expressed almost exclusively through this biological envelope we call the human body ${ }^{3}$.

But even this very basic underpinning is now being challenged by the expansion of our notion, not of reality, which we always knew to be subjective, but of the layers of reality. In fact, science and technology have shown that even the very foundational understanding of the fabric of individuality (our evolutionary carved body) is not wrong as much as it is skewed and limited. We are not discrete units, we do not exclusively belong to a species, and we are not well-delineated individuals, science tells us ${ }^{4}$. The very idea of humanity, this collective of men and women, each slightly different and slightly unique, each thought to be conscious and capable of self-awareness, does not appear to clearly address what homo sapiens truly is ${ }^{5}$.

Why are we? What are we? What is "we"? How do we understand and conceptualize the world and the very notion of our awareness? Is there any truth, reality, or existence outside of our thoughts and bodies, beyond our codes? We have asked these questions for a long time, probably as soon as signs and symbols materialized from our hands and minds. And while it would be foolish to believe that definite answers could be found here, my goal is to craft a path that may lead to a renewed series of queries and thought processes from which to ponder these critical problems.

This said, my proposal is bound to a specific history, one that includes La Mettrie, sensualists, empiricists and compatibilists. My premise is that seeing and understanding reality is only possible through the material world. Ideas, consciousness, and Being are "material" products of evolutionary pressures. We are molded by our biological desires, thrusts, and functions. We are biologically determined ${ }^{6}$.

Many, of course, will challenge these notions and suggest, as Stuart Kauffman does [8], that reductionism cannot explain the manyfaceted richness of our world: from the atom, contends Kauffman, one cannot predict morality, culture, ethics and justice. But this, I believe, is a mistake. Trying to predict the emergence of culture using the atom is no different than attempting to forecast

2 "And evolutionarily speaking, there is seldom any mystery in why we seek the goals we seek—why, for example, people would rather make love with an attractive partner than get a slap on the belly with a wet fish. The things that become objects of desire are the kinds of things that led, on average, to enhanced odds of survival and reproduction in the environment in which we evolved: water, food, safety, sex, status, mastery over the environment, and the well-being of children, friends, and kin." ([3], p. 143)

3 "Your brain and body, the vehicles that make 'choices', are composed of molecules, and the arrangement of those molecules is entirely determined by your genes and your environment. Your decisions result from molecular-based electrical impulses and chemical substances transmitted from one brain cell to another. These molecules must obey the laws of physics, so the outputs of our brain —our 'choices' - are dictated by those laws. (It's possible, though improbable, that the indeterminacy of quantum physics may tweak behavior a bit, but such random effects can't be part of free will.) And deliberating about your choices in advance doesn't help matters, for that deliberation also reflects brain activity that must obey physical laws. To assert that we can freely choose among alternatives is to claim, then, that we can somehow step outside the physical structure of our brain and change its workings. That is impossible. Like the output of a programmed computer, only one choice is ever physically possible: the one you made. As such, the burden of proof rests on those who argue that we can make alternative choices, for that's a claim that our brains, unique among all forms of matter, are exempt from the laws of physics by a spooky, nonphysical 'will' that can redirect our own molecules." [4].

4 "A taxonomist can clearly sort out the difference between a colobus monkey, a baboon, a chimpanzee, a gorilla, and a human, yet the traits that permit us to classify these animals as distinct are, as I've mentioned, often irrelevant for a microbe. From the perspective of a virus, if cells from distinct species share the appropriate receptors, and ecological connections provide the appropriate opportunities to make a jump, the fur of a baboon or the upright status of a human does not matter at all." [5].

5 "These studies show that you can't understand an animal's evolution simply by considering the evolutionary pressures that act on its genome. You also have to consider the genes of the bacteria and other passengers that live inside it. We're each like a superorganism - a unified alliance between the genes of several different species, only one of which is human." [6].

6 "When your biology changes, so can your decision-making and your desires. The drives you take for granted ('I' $\mathrm{m}$ a heterosexual/homosexual,' 'I'm attracted to children/adults,' 'I'm aggressive/not aggressive,' and so on) depend on the intricate details of your neural machinery. Although acting on such drives is popularly thought to be a free choice, the most cursory examination of the evidence demonstrates the limits of that assumption." [7]. 
traffic by examining a piston. Culture and humanity, acquire meaning after the fact, and are not pre-ordained patterns. While culture cannot be predicted by the atom, it is nonetheless its "natural" result.

Humanity, we all agree, is the product of large natural phenomena (survival; the microcosm; geology; chemistry; physics, etc.). My argument, though, is slightly different: If Being, and consciousness are the products of complex forces, then one must also consider the possibility that machines, technology, data, and non-sentient natural phenomena (such as parasites, viruses, and bacteria) are central to what humanity is and what humanities must examine. Technology, data, and machines have now embedded themselves within evolutionary patterns. Humans are machines, many philosophers have claimed. But machines are also human, I will argue.

\section{The Reframing}

The microbiome, evolutionary pressures, the reframing of species through permeable and communicative layers of bacteria and viruses ${ }^{7}$, new understandings of what seems like conscious decision-making by insentient beings (such as social insects, bacteria and viruses) ${ }^{8}$, our alleged inability to clearly establish the causational relationship between thoughts and actions (between the desire to do and the actual doing) ${ }^{9}$, the stunning fact that organisms without brains, such as plants [11], seem capable of intelligent behaviour, the constant mediation of our world by technology (to the point where it is metaphorically becoming the third hemisphere of our brains), all clearly suggest the need for a fundamental examination of our notion of individuality. The sharp, well-defined, distinct and autonomous unit that we perceive to be the individual human, animal or plant, is a temporary, permeable, and malleable phenomenon, resulting from a very basic biological thrust for reproduction

7 "Modern research hints that primordial communities of bacteria were elaborately interwoven by communication links. Their signalling devices would have been many: chemical outpourings with which one group transmitted its findings to all in its vicinity; fragments of genetic material drifting from one end to the other of the community. And a variety of other devices for long-distance data broadcasting. These turned a colony into a collective processor for sensing danger, for feeling out the environment, and for undergoing —if necessary — radical adaptations to survive and prosper. The resulting learning machine was so ingenious that Eshel Ben-Jacob has called its modern bacterial counterpart a 'creative web'. ( ... ) Overcoming disaster sometimes involved plugging in prefabricated twiss of DNA and reverting to ancestral strategies. When tricks like this didn't work and the stakes were life or death, the millions-and often trillions-of bacteria in a colony used their individual genomes, says Ben-Jacob, as individual computers, meshing them together, combining their data, and forming a group intelligence capable of literally reprogramming their species' shared genetic legacy in ways previously untried and previously unknown." [9].

8 "How viruses choose when to launch themselves remains largely unknown, but they almost certainly monitor the environmental variables of their world when making these decisions. Many of the adult humans who are infected with herpes simplex virus know that stress can bring on cold sores. Some also have noted anecdotally that pregnancy seems to bring on active infections. While still speculation, it would not be surprising if viruses responded to environmental cues indicating severe stress or pregnancy by activating. Since severe stress can indicate the possibility of death, it may be their last opportunity to spread - a dead host is also a dead virus. A pregnancy, on the other hand, presents the opportunity for spread either through genital contact with the baby during childbirth or during the kissing that inevitably follows the birth of a baby. ( . . . ) The careful timing that viruses and other microbes use when choosing to spread does not differ from the choices that other organisms make. Whether the timing of fruiting in a tropical fruit tree or the timing of mating in water buffalo, living things that time their reproduction appropriately have more successful offspring. This means the traits for accurately timing reproduction will persist and diversify. And how microbes time their growth within our bodies also has a major impact on illness." [5].

9 "The theory of apparent mental causation, then, is this: People experience conscious will when they interpret their own thought as the cause of their action (Wegner and Wheatley 1999). This means that people experience conscious will quite independently of any actual causal connection between their thoughts and their actions." [10] "This means, though, that conscious will is an illusion. It is an illusion in the sense that the experience of consciously willing an action is not a direct indication that the conscious thought has caused the action. ( ... ) The processes of mind that produce the experience of will may be quite distinct from the processes of mind that produce the action itself. As soon as we accept the idea that the will should be understood as an experience of the person who acts, we realize that conscious will is not inherent in action-there are actions that have it and actions that don't. ( . . . ) The mind creates this continuous illusion; it really doesn't know what causes its own actions. ( . . ) Spinoza in The Ethics (1677), 'Men are mistaken in thinking themselves free; their opinion is made up of consciousness of their own actions, and ignorance of the causes by which they are determined. Their idea of freedom, therefore, is simply their ignorance of any cause for their actions' ([10], part. II, p. 105)." 
and survival, science is clearly telling us ${ }^{10}$. We "see" individuals only because we can then establish clear behavioural patterns that guarantee reproduction and survival. In fact, current scientific research suggests that the very idea of individuality, the conceptual notion of distinct units, is incorrect. There are no individuals, there is no single will, there is no consciousness capable of pulling away from instinctive physical reactions ${ }^{11}$, there is not even such a thing as a single species ${ }^{12}$. We are, it seems, but ephemeral forms in a continuum that extends from the microcosm to the macrocosm ${ }^{13}$, a fleeting whirlpool that forms out of the endless ebb and flow of the many-layered levels of reality ${ }^{14}$.

$90 \%$ of our genes are not ours but bacterial; close to $10 \%$ of our DNA is made of viruses; parasites have been shown to manipulate and modify behaviour; even the basic structure of what makes us mammals (the placenta) is now believed to have been created by a virus ${ }^{15}$. We are nothing, it appears, but layers of microorganisms. In fact, we seem to be doing only what our microbiome tells us to do, in all fields of human endeavours. Free will, love, the arts, our longing for the sublime, the thirst for knowledge, the need for community, language, any and all of these activities, which we once believed to be clear evidence of our humanness, are now alleged to be different pressures and forces thrust upon us, imposed on us, carved in us by both evolution and the microbiome ${ }^{16}$.

The world we see, hear, touch, smell, and taste is sensory input data being filtered and structured by the brain, itself a complex system of electrical and chemical elements, no different from a bacterial network, a social insect system, the Internet. Could our humanity, our memories, our personality, our ability to express love and act with generosity or cruelty be nothing, then, but mechanical, chemical

10 "There are colonies, such as those of corals or of Hydroid polyps, where a number of animals, each of which by itself would unhesitatingly be called an individual, are found to be organically connected, so that the living substance of one is continuous with that of all the rest. Sometimes these apparent individuals differ among themselves and their energies are directed not to their own particular needs, but to the good of the colony as a whole. Which is the individual now?" ([12], p. 75).

11 "The self, an actor in a perpetually changing drama, lacks full command of its own actions. It does not make decisions solely by conscious, purely rational choice. Much of the computation in decision making is unconscious, strings dancing the puppet ego. Circuits and determining molecular processes exist outside conscious thought. They consolidate certain memories and delete others, bias connections and analogies, and reinforce the neurohormonal loops that regulate subsequent emotional response. Before the curtain is drawn and the play unfolds, the stage has already been partly set and much of the script written." ([13], p. 130).

12 "The human body isn't besieged; it's saturated, infused, with microbial life at every level. 'There is no such thing as an individual,' Lynn Margulis, a biologist at the University of Massachusetts at Amherst, told me recently. 'What we see as animals are partly just integrated sets of bacteria."' [14].

13 "By now, all faith in man as a guide to individuality must have been shattered. In man, individuality presents itself as something definite and separate from all others, something which animates a particular mass of matter and is inflexibly associated with it, appearing when it appears and vanishing when it dies. That idea of individuality is not universally applicable. In perplexing procession before us there have appeared individualities inhabiting single cells, others inhabiting single cells at the start, many cells in later life; individualities whose fleshly mansions are continuous one with another, no boundaries between; individualities that appear and disappear along an undying stream of substance, the substance moulding itself to each as the water of a stream is moulded in turn to each hollow of its bed; within one individuality others infinite in number, lying hid under the magic cloak of potentiality, but each ready to spring out as if from nowhere should occasion offer. Nothing remains but to abandon preconceived ideas." ([12], p. 80).

14 "Rather than trying to figure out how viruses are not like other living things, it may be more useful to think about how viruses and other organisms form a continuum. We humans are an inextricable blend of mammal and virus." [15] "There is no ' $\mathrm{I}$ ' for a person, for a beehive, for a corporation, for an animal, for a nation, for any living thing. The ' $\mathrm{I}$ ' of a vivisystem is a ghost, an ephemeral shroud. It is like the transient form of a whirlpool held upright by a million spinning atoms of water." ([16], p. 44).

15 "If not for a virus, none of us would ever be born. In 2000, a team of Boston scientists discovered a peculiar gene in the human genome. It encoded a protein made only by cells in the placenta. They called it syncytin. The cells that made syncytin were located only where the placenta made contact with the uterus. They fuse together to create a single cellular layer, called the syncytiotrophoblast, which is essential to a fetus for drawing nutrients from its mother. The scientists discovered that in order to fuse together, the cells must first make syncytin. What made syncytin peculiar was that it was not a human gene. It bore all the hallmarks of a gene from a virus." [17].

16 "Human neuroimaging studies have convincingly shown that the brain areas involved in aesthetic responses to artworks overlap with those that mediate the appraisal of objects of evolutionary importance, such as the desirability of foods or the attractiveness of potential mates. (...) There is virtually no evidence that artworks activate emotion areas distinct from those involved in appraising everyday objects important for survival. Hence, the most reasonable evolutionary hypothesis is that the aesthetic system of the brain evolved first for the appraisal of objects of biological importance, including food sources and suitable mates, and was later co-opted for artworks such as paintings and music." [18]. 
and physical interactions between our microorganisms and the environment? Are we nothing but fleeting, unconscious, automated swarm systems? ${ }^{17}$

What about technology, one could argue? Isn't it the perfect expression of our humanity, the ultimate proof of our ability to act independently, consciously, rationally, beyond evolutionary needs? Isn't our ability to develop tools, machines and systems to enrich, not nature, not the world, not the structure of evolution and the need for survival, but only civilisation, clear evidence of our extraordinary humanity? If everything is the expression of evolution, if everything is the mechanical crystallisation of our microorganisms, how can one, then, justify technology?

Our mistake, many would suggest, is one of confusing the end with the means. We assume that the expression of our world, its "goals", its "direction" (if one can use such terms) is the development and expansion of organically-based life forms. But organically-based life forms are a means not an end. We don't know what the end is, if there is even such a thing. What we do know is that our planet, what we know of outer space, what we understand of the laws of physics and the principles of chemistry strongly suggest that life is the expression of more fundamental laws: that of the complexification, and multiplication of information ${ }^{18}$; that of movement in time and space; and that of pushing against entropy, laws that have nothing to do with the preservation of organic life forms.

Why, then, would the microbiome drives us to create technology? Only because technology expresses these laws in quicker and more efficient ways than biology (at the expense of resiliency, which is why organic matter is still abundant), computer scientists and evolutionary theorists would argue. In fact, they would contend, machines, computer, and the Internet are nothing but different embodiments of the aforementioned laws. Moreover, if one looks at the world today, one clearly sees patterns of intersection between biology and technology: machines proliferate at a rate similar to those of insects ${ }^{19}$; they clearly co-evolve with humans, as many microorganisms do; they adapt to changes in the environment; they sculpt the ecosystem to their needs. Ultimately one may argue, machines like organic life, are ephemeral and transient whirlpools embedded in the planet's continuum.

\section{Humanities in the 21st Century}

What does it mean, then, to be human in the 21st century?

It probably means that humanity can only be understood through its intertwining with technology and the microbiome. It possibly means that individual men and women are temporary expressions of information, fleeting embodiments of multiplication and complexity, short-lived vortexes of technological and microbiological whirlwinds. It conceivably means, in our case and for the sake of this argument, that one cannot talk of humanities in the 21st century using conventional notions of individuality, free will, and consciousness ${ }^{20}$; that one must now consider phenomenology as the

17 "Biologists once thought that human beings were physiological islands, entirely capable of regulating their own internal workings. ( ... ) Over the past 10 years or so, however, researchers have demonstrated that the human body is not such a neatly, self-sufficient island after all. It is more like a complex ecosystem—a social network—containing trillions of bacteria and other microorganisms that inhabit our skin, genital areas, mouth and especially intestines." ([19], p. 22).

18 "In Langton's view, the transfer and retention of information is an essential characteristic of life. 'It's clear that most of the living things we know are physical embodiments of information processing entities,' he later explained. 'A good deal of what they do is based on processing information—not just materials, not just energy but information. Living organisms use information in order to rebuild themselves, in order to locate food, in order to maintain themselves by retaining internal structure... the structure itself is information." ([20], p. 108).

19 "We know from mathematics that systems containing very, very large numbers of parts behave significantly different from systems with fewer than a million parts. Zillionics is the state of supreme abundance, of parts in the many millions. The network economy promises zillions of parts, zillions of artifacts, zillions of documents, zillions of bots, zillions of network nodes, zillions of connections, and zillions of combinations. Zillionics is a realm much more at home in biology-where there have been zillions of genes and organisms for a long time- than in our recent manufactured world. Living systems know how to handle zillionics. Our own methods of dealing with zillionic plentitude will mimic biology." ([21], p. 46).

20 "When we set out to explain our actions, they are all post hoc explanations using post hoc observations with no access to nonconscious processing. Not only that, our left brain fudges things a bit to fit into a makes-sense story. It is only when the stories stray too far from the facts that the right brain pulls the reins in. These explanations are all based on what makes it into our consciousness, but the reality is the actions and the feelings happen before we are consciously aware of them-and 
product of machines, parasites, bacteria, and viruses; that one probably cannot argue for humanities without arguing for the disappearance of humanity; and that to be human is to live with, in and through, thinking by and with AI, bacteria, software, viruses (both organic and inorganic ${ }^{21}$ ), hardware, machine language, parasites, big data, monitors, pixels, swarms systems and the Internet.

The question for us then is the following: If a 21st century human being is a fleeting form made of machines, the microbiome, evolutionary needs and forces, social constructs, strange feedback loops (such as stigmergy ${ }^{22}$ ), and large, intelligent swarm systems ${ }^{23}$ that acts on the world without consciousness on the basis of simple goals and physical laws, what does it mean, then, to explore ethics, aesthetics, the spiritual nature of humanity, humanity itself? What does it mean in terms of education and the way we built our education system? What does it mean in terms of social justice? If we are only systems, if our consciousness is essentially a narrative that act after the fact, after our many different systems have quantified the world, reacted and adapted to it, what then is the pursuit of knowledge? If we are controlled by the microbiome and are only temporary constructs in the ebb and flow of a continuum, what, then, is the narrative of humanity, the storyline of the humanities?

This is our biggest challenge. While quantum physics, evolutionary biology, genomics, neuroscience and epigenetics continue to reframe, deconstruct and shatter our limited, linear, delineated and causal understanding of the world, unhinge our notion of the self, of gender, of

most of them are the results of nonconscious processes, which will never make it into the explanations. What was interesting was that the left hemisphere did not say, 'I don't know,' which truly was the correct answer. It made up a post hoc answer that fit the situation. It confabulated, taking cues from what it knew and putting them together in an answer that made sense. We called this left-hemisphere process the interpreter. Ramachandran suggested that various defense mechanisms, such as rationalization (creating fictitious evidence or false beliefs) and repression, arise because the brain arrives at the most probable and globally consistent interpretation of evidence derived from multiple sources, and then ignores or suppresses conflicting information. The interpreter that weaves our story only weaves what makes it into consciousness. Because consciousness is a slow process, whatever has made it to consciousness has already happened. It is a fait accompli. As we saw in my story at the beginning of the chapter, I had already jumped before I realized whether I had seen a snake or if it was the wind rustling the grass. What does it mean that we build our theories about ourselves after the fact? How much of the time are we confabulating, giving a fictitious account of a past event, believing it to be true?" [22] "The physiologist Benjamin Libet famously used EEG to show that activity in the brain's motor cortex can be detected some 300 milliseconds before a person feels that he has decided to move. Another lab extended this work using functional magnetic resonance imaging (fMRI): Subjects were asked to press one of two buttons while watching a 'clock' composed of a random sequence of letters appearing on a screen. They reported which letter was visible at the moment they decided to press one button or the other. The experimenters found two brain regions that contained information about which button subjects would press a full 7 to 10 seconds before the decision was consciously made. More recently, direct recordings from the cortex showed that the activity of merely 256 neurons was sufficient to predict with 80 percent accuracy a person's decision to move 700 milliseconds before he became aware of it. ( . . ) We do not know what we intend to do until the intention itself arises. ( ... ) You are not controlling the storm, and you are not lost in it. You are the storm." [23].

21 "For although we do not consider computer viruses alive, computer viruses satisfy most of the qualifications above. They are a pattern that reproduces; they include a copy of their own representation; they capture computer metabolistic (CPU) cycles; they can die, and they can evolve. We could say that computer viruses are the first examples of emergent artificial life." ([16], p. 346) Cohen believed that his own virus as literally alive. When the field of artificial life coalesced in 1987, that claim was taken seriously. The a-life scientists generally agreed that, of all information organisms, none came so close to fulfilling the admittedly vague demands of life as did computer viruses. Essentially computer viruses were the first organisms to contend for what was known as the 'Strong Claim' to artificial life. This held, according to Chris Langton, 'that any definition or list of criteria broad enough to include all known biological life will also include certain class of computer processes, which, therefore, will have to be considered 'actually' alive.' (The 'Weak Claim' held that, although a-life experiments were potentially useful simulations of the processes of life, the nature of living systems dictated that they could never themselves become instances of life)." ([20], p. 326).

22 "Stigmergy is a mechanism of indirect coordination between agents or actions. The principle is that the trace left in the environment by an action stimulates the performance of a next action, by the same or a different agent. In that way, subsequent actions tend to reinforce and build on each other, leading to the spontaneous emergence of coherent, apparently systematic activity. Stigmergy is a form of self-organization. It produces complex, seemingly intelligent structures, without need for any planning, control, or even direct communication between the agents. As such it supports efficient collaboration between extremely simple agents, who lack any memory, intelligence or even individual awareness of each other." [24].

23 "What makes possible the uncanny coordination of these murmurations, as starling flocks are so beautifully known? Until recently, it was hard to say. (...) Starling flocks, it turns out, are best described with equations of "critical transitions" - systems that are poised to tip, to be almost instantly and completely transformed, like metals becoming magnetized or liquid turning to gas. Each starling in a flock is connected to every other. When a flock turns in unison, it's a phase transition. (...) Starlings may simply be the most visible and beautiful example of a biological criticality that also seems to operate in proteins and neurons, hinting at universal principles yet to be understood." [25]. 
species and of free will, the humanities will have to suggest a new narrative, one that makes sense of the (un)natural world. A new chronicle of humanity is now needed, one that expands at the cusps of the event horizon, one that features extreme notions of the world, one that includes radical concepts of what life is, of what the human species is not, and of how parasites power us to act in certain ways [26], with our need to act as if we had free will, to long as if love was more than just chemical reactions to evolutionary clues, to believe we can actually create a better, kinder and more empathic civilisation. This will neither be easy nor quick. But I believe it to be fundamental. My argument is that the most crucial mistake we could make would be to cling to our old notions of humanity and the humanities, to argue against these new perceptions, to deny the almost total control of the microbiome on our behaviour, to claim an unidentifiable exclusiveness to humanity, to use the world of art, poetry, music, and aesthetics (all perfectly explainable as evolutionary systems ${ }^{24}$ ) to defend an already broken-through, invaded and burned out fortress.

What would such a new definition of the humanities look like?

Let me suggest the following: The new humanities should speak of, argue for, understand and embrace a new human being, one who is a collective of microorganisms, one who exists as a fleeting evolutionary form, one for whom free-will and consciousness are only part and parcel of a larger continuum, and are only the result and the expression of a system that extends from the microcosm to the macrocosm, a dynamic structure that encompasses the laws of physics and the bonds of chemistry and is the result of phenomena that far outreach the individual and the species.

It is humanities expanded. The human species, it appears, must now be extended to the microcosm, to the microbiome, to technology, and to phenomena that we consider neither conscious nor alive. Ethics, justice, empathy, melancholia, and the drive to understand must now probably include, and take into account the world of viruses, parasites, bacteria, AI, robots, computers, and machines.

It may seem hard to fathom. But if one agrees that these phenomena have a direct and powerful impact and influence on humanity, if one argues, further, that their roots allow for the tree of humankind to exist, grow and expand, one, then, must also agree that to treat them as outside forces that have nothing to do with humanity is a dangerous game to play. If one believes that the ecosystem is worthy of justice and reverence, then one should probably also agree to include other dimensions of the natural world previously dismissed because of size, differences in material, or our inability to categorize their complexity into the circle of humanity.

What does it mean? It means, dramatically and counter-intuitively, developing notions of justice, ethics and respect for our soon to be ubiquitous robots; understanding and treating the Internet as we would any other natural system; accepting that the microbiome is a living ecosystem as important and as deserving of respect as is the Amazon forest; and developing a narrative of what it is to be human which will include these strange phenomena. We are humans, I would argue, because we now experience reality through a third hemisphere, because our bacterial flora is part and parcel of our thoughts, because the intrusion of viruses in our DNA dictates how we behave, because evolution, and its innumerable variables, create the push and the need for love, aesthetics, and beauty.

Soon, machines will make ethical decisions for us, as the Google car is making clear. Soon, machines will have the ability to learn, reflect, pause, and create moving artworks [28]. Soon, machines will be active participants in our ethical discussions and dilemmas [29]. But soon machines will

24 "We can say that the experience of beauty is one of the ways that evolution has of arousing and sustaining interest or fascination, even obsession, in order to encourage us toward making the most adaptive decisions for survival and reproduction." ( ... ) "Hand axes mark an evolutionary advance in human history, tools fashioned to function as what Darwinians call fitness signals. That is to say, displays that are performances, like the peacock's tail, except that unlike hair and feathers the hand axes are consciously cleverly crafted. Competently made hand axes indicated desirable personal qualities. Intelligence, fine motor control, planning ability, conscientiousness, and sometimes access to rare materials. You know it's an old line but it has been shown to work-why don't you come up to my cave so I can show you my hand axes? From Blasco to the Louvre to Carnegie Hall, human beings have a permanent, innate taste for virtuoso displays in the arts. We find beauty in something done well." [27]. 
probably also be taken over, modified and deeply influenced by the microbiome. In the near future, machines and the microbiome will possibly merge and be undistinguishable from one another. Soon, distinguishing the inorganic from the organic, the conscious from the seemingly insentient, the neuronally from the algorithmally gifted, species from machines will probably become impossible.

Technology and the microbiome will expand our notion of the innumerable and intertwined layers of reality. Quantum physics already suggests the implausible entanglement of atoms. Soon, the unseen physical material of the universe, what we currently call dark matter, will open up new understandings of the physical world. Already, machines are creating data at a rate that is impossible for the human brain to comprehend, or make sense of. Being human will soon mean being an entangled piece of a large, convoluted, complex and infinitely multifaceted world. Extricating humanities from this entanglement is, I believe, a grave mistake. Humanities in the 21st century could be humanities of men, women, machines, parasites, viruses, bacteria, evolution, dark matter and atomic forces. Humanities in the 21st century could be humanities that understand that if man and woman are but a small but critical piece of a larger puzzle, perfectly integrated into that puzzle, then what man and woman need, hope for, desire, and long for, justice, ethics, and respect are also common to all phenomena, are also the results of mechanisms deprived of what we consider to be free-will. Perhaps, humanities in the 21st century should give credence to the notions that our very basic grasp of consciousness, intent and agency can only be the results of large unconscious systems, that our ability to self-reflect, to contemplate, and to be moved by aesthetics are the results of the innumerable living organisms deep within our fabric, the same living organisms, the same microscopic and macroscopic systems, the same evolutionary forces that permeate all dimensions of reality, all layers of life, all expressions of nature, technology, and the natural world. Our experiences are most probably not specific to our species but universal, expressed and mediated differently, yes but common to all living organisms, all systems, and all expressions of nature. Humanities then, instead of being unique to humans could actually be the universal matrix needed to understand the ecosystem, the framework applied to all expressions of nature and evolution.

\section{Conclusions}

Pleasure as David P. Barash would say, "is not something that nature doles out without reason and we would expect this reason to be intimately linked to maximising fitness" [30]. If this is the case, then the pleasure of thinking, reflecting, questioning; the pleasure of being moved, touched, saddened; the pleasure of creating, modifying, manufacturing; the pleasure of building a just society, one that constantly expands the circle of empathy, are not unique to humans. In fact, the desire for justice, the needs for ethics, the longing for compassion may be universal traits that all living organisms and all systems share. The humanities of the future could include every organism, every system (organic and non organic), and every technology. Imagine what such humanities would look like, imagine how exciting building such humanities will be, imagine how complex and complicated that task will be, but also imagine how fruitful, how encompassing, and how pleasurable it may be to achieve what we have longed for, for thousand of years: folding the human back into the world.

The humanities of the 21st century is the universe. This, I believe, is its future.

Conflicts of Interest: The author declares no conflict of interest.

\section{References}

1. Jill Sisson Quinn. "Sign Here if You Exist." In The Best American Science and Nature Writing 2011. Boston: Houghton Mifflin Company, 2011, pp. 274-90.

2. Ray Kurzweil. The Singularity Is Near: When Humans Transcend Biology. New York: Penguin Books, 2006.

3. Steven Pinker. How the Mind Works. New York: W.W. Norton \& Company, 1999.

4. Jerry A. Coyne. "You Don't Have Free Will." The Chronicle Review, 18 March 2012. Available online: http://chronicle.com/article/Jerry-A-Coyne/131165/ (accessed on 10 March 2013). 
5. Nathan Wolfe. The Viral Storm: The Dawn of a New Pandemic Age. Cornwall: Times Books, 2011.

6. Ed Yong. "An introduction to the microbiome." 8 August 2010. Available online: http://blogs.discovermagazine. com/notrocketscience/2010/08/08/an-introduction-to-the-microbiome/ (accessed on 22 March 2013).

7. David Eagleman. “The Brain on Trial." Atlantic Monthly, July-August 2011. Available online: http://www.theatlantic. com/magazine/archive/2011/07/the-brain-on-trial/8520/ (accessed on 11 March 2013).

8. Stuart Kauffman. Reinventing the Sacred. New York: Basic Books, 2008.

9. Howard Bloom. Global Brain. New York: Willey, 2001, pp. 17-18.

10. Daniel M. Wegner. The Illusion of Conscious Will. Cambridge: MIT Press, 2003.

11. Science et vie. L'intelligence des Plantes enfin Révélée. Paris: Mondadori Magazines, 2013, pp. 65-66.

12. Connie Barlow, ed. From Gaia to Selfish Genes. Cambridge: MIT Press, 1992.

13. Edward O. Wilson. Consilience the Unity of Knowledge. New York: Vintage Books, 1990.

14. Burkhard Bilger. "Nature's Spoils." In The Best American Science and Nature Writing 2011: The Best American Series. Edited by Mary Roach and Tim Folger. Boston: Houghton Mifflin Harcourt, 2011.

15. Carl Zimmer. A Planet of Viruses. Chicago: University of Chicago Press, 2012.

16. Kevin Kelly. Out of Control: The Rise of Neo-Biological Civilization. Boston: Addison-Wesley Publishing Company, 1994.

17. Carl Zimmer. "Mammals Made by Viruses." 14 February 2012. Available online: http://blogs.discovermagazine. com/loom/2012/02/14/mammals-made-by-viruses/ (accessed on 6 April 2013).

18. Steven Brown, and Xiaoqing Gao. "The Neuroscience of Beauty-How does the brain appreciate art?" 27 September 2011. Available online: http://www.scientificamerican.com/article.cfm?id=theneuroscience-of-beauty (accessed on 3 March 2013).

19. Jennifer Ackerman. "The Ultimate Social Network." Scientific American 306 (2012): 22-27. [CrossRef]

20. Steven Levy. Artificial Life. New York: Random House, 1992.

21. Kevin Kelly. New Rules for a New Economy. New York: Viking, 1998.

22. Michael S. Gazzaniga. Who's in Charge? Free Will and the Science of the Brain. New York: Harper Collins, 2011.

23. Sam Harris. Free Will. New York: Free Press, 2012.

24. Wikipedia. "Stigmergy." Available online: https://en.wikipedia.org/wiki/Stigmergy (accessed on 18 February 2013).

25. Brandon Keim. "The Startling Science of a Starling Murmuration." November 2011. Available online: http:/ /www.wired.com/wiredscience/2011/11/starling-flock/ (accessed on 6 April 2013).

26. Kathleen McAuliffe. "How Your Cat Is Making You Crazy." Atlantic Monthly, March 2012. Available online: http:/ / www.theatlantic.com/magazine/archive/2012/03/how-your-cat-is-making-you-crazy/8873/ (accessed on 20 February 2013).

27. Denis Dutton. “Are We Hard-Wired For Beauty?" Ted Radio Hour, 16 April 2013. Available online: http:/ / www.npr.org/templates/transcript/transcript.php?storyId=177490162 (accessed on 20 March 2013).

28. Chris Wilson. "I'll be Bach." Slate, 19 May 2010. Available online: http://www.slate.com/articles/ arts/music_box/2010/05/ill_be_bach.single.html (accessed on 15 June 2013).

29. Will Knight. "How to Help Self-Driving Cars Make Ethical Decisions." MIT Technology Review, 29 July 2015. Available online: http:/ / www.technologyreview.com/news/539731/how-to-help-self-drivingcars-make-ethical-decisions / (accessed on 3 August 2015).

30. David P. Barash. “Animal Magnetism.” Aeon Magazine, 13 May 2014. Available online: http://aeon.co/ magazine/nature-and-cosmos/why-humans-evolved-to-love-watching-animals/ (accessed on 20 May 2013).

(C) 2016 by the author; licensee MDPI, Basel, Switzerland. This article is an open access article distributed under the terms and conditions of the Creative Commons by Attribution (CC-BY) license (http://creativecommons.org/licenses/by/4.0/). 